Marquette University

e-Publications@Marquette

Biological Sciences Faculty Research and

Publications

Biological Sciences, Department of

$11-1-1983$

Germ Line-Specific DNA Sequences are Present on All Five Micronuclear Chromosomes in Tetrahymena thermophila

Kathleen M. Karrer

Marquette University, kathleen.karrer@marquette.edu

Published version. Molecular and Cellular Biology, Vol. 3, No. 11 (November 1983): 1909-1919.

Permalink. (C) 1983 American Society for Microbiology. Used with permission. 


\title{
Germ Line-Specific DNA Sequences Are Present on All Five Micronuclear Chromosomes in Tetrahymena thermophila
}

\author{
KATHLEEN M. KARRER \\ Department of Biology, Brandeis University, Waltham, Massachusetts 02254
}

Received 19 May 1983/Accepted 16 August 1983

\begin{abstract}
The development of the macronucleus from the zygotic micronucleus in the ciliated protozoan Tetrahymena spp. involves the elimination of specific DNA sequences (M. C. Yao and M. Gorovsky, Chromosoma 48:1-18 1974). The present study demonstrates that micronucleus-specific DNA is present on all five of the micronuclear chromosomes. Fragments of micronuclear DNA from Tetrahymena thermophila were cloned in the plasmid vector $\mathrm{pBR} 322$. A procedure was developed to examine the organization of the cloned sequences in micro- and macronuclear DNA without nick translating each individual probe. Twenty-three percent of randomly selected DNA sequences examined by this method were micronucleus (germ line) specific. They were all members of families of repeated sequences. Hybridization of six micronucleus-specific DNA sequences to micronuclear DNA from nullisomic strains of $T$. thermophila, which are lacking one or more pairs of chromosomes in the micronucleus, suggested that these sequences are present on several chromosomes. One micronucleus-specific sequence was shown by in situ hybridization to be present on all five of the micronuclear chromosomes.
\end{abstract}

The ciliated protozoa of the genus Tetrahymena contain a diploid germ line micronucleus and a polyploid macronucleus, which is responsible for most, if not all, of the transcriptional activity in a vegetative cell. During sexual reproduction (conjugation), the macronucleus is destroyed and is replaced by a new macronucleus which develops from one of the mitotic products of the zygotic micronucleus. The development of the new macronucleus involves extensive genome reorganization, including polyploidization of the bulk of the genome to the level of $45 \mathrm{c}$, amplification of the genes which code for 17S and 25S rRNA, and the possible fragmentation of the chromosomes into subchromosomal elements (for a review, see reference 12). Renaturation kinetics of micro- and macronuclear DNA suggest that 10 to $20 \%$ of the micronuclear DNA is eliminated during the formation of the macronucleus and that most of these sequences are repeated on the order of 100 times in the micronuclear genome (34).

Several micronucleus-specific (mic-specific) DNA sequences have been isolated on the basis of linkage in the micronuclear genome to the sequence C-C-C-C-A-A. This hexanucleotide occurs in blocks of tandem repeats which have very different arrangements in the micro- and macronuclear genomes (31). $\mathrm{C}_{4} \mathrm{~A}_{2}$ repeats occur predominantly at the ends of DNA molecules in the macronucleus $(6,36)$. The $C_{4} A_{2}$ repeats which have been isolated from micronuclear DNA thus far are all flanked by mic-specific DNA sequences. At least one single-copy micspecific sequence and several families of repeated mic-specific sequences have been identified by this approach $(6,30)$.

Very little is known about the mechanisms whereby some DNA sequences are eliminated from the developing macronucleus and others are retained. One possible model would invoke underreplication and subsequent dilution of the mic-specific sequences in the macronuclei of dividing cells. However, Yokoyama and Yao (37) have presented evidence that mic-specific DNA is replicated a few times early in the formation of the macronuclear anlagen and then is eliminated, presumably by specific degradation, before any nuclear division occurs.

The localization of mic-specific DNA sequences on the five micronuclear chromosomes of Tetrahymena spp. places constraints on the mechanism of chromatin diminution in this organism. If all of the mic-specific DNA sequences, and only mic-specific DNA, are present on one of the five micronuclear chromosomes, that chromosome can be completely eliminated from the macronuclear genome. Alternatively, if micspecific DNA sequences were present on several of the micronuclear chromosomes, then some fragmentation of the genome must occur during the development of the macronucleus to sepa- 
rate DNA sequences which are eliminated from those which are retained.

Two kinds of evidence support the latter model. First, there is a single copy of the $17 \mathrm{~S}$ and $25 \mathrm{~S}$ RNA-coding sequences (rDNA) in the micronucleus of Tetrahymena spp. It is excised from the genome (32) and amplified several hundredfold in the macronucleus (35), where it is present in the form of 21-kilobase (kb) extrachromosomal inverted repeats $(9,10,16)$. Excision of the rDNA from the micronuclear chromosome involves chromosome breakage with the elimination of $2.8 \mathrm{~kb}$ of flanking DNA and the generation of a free chromosome end in the macronucleus (29). Thus, one mic-specific sequence lies between the only DNA sequence which has been shown to be highly amplified in the macronuclear DNA and a sequence which will be converted to a telomere. Second, Yao (30) hybridized a mic-specific sequence to micronuclear DNA from a strain which lacks three of the five micronuclear chromosomes. The probe hybridized to a subset of the bands which appear in the micronuclear DNA from a wildtype cell, suggesting that some, but not all, copies of that sequence were present on one or more of the chromosomes 2,3 , and 5 .

The work described here extended that observation by a systematic analysis of six different mic-specific sequences selected at random. They were hybridized to micronuclear DNA from seven nullisomic strains of Tetrahymena thermophila which, taken together, cover the entire genome. The results indicated that none of these sequences, which are each repeated in the genome, was located exclusively on any one chromosome. These results were confirmed by in situ hybridization, which showed that at least one of these sequences is present on all five chromosomes.

\section{MATERIALS AND METHODS}

Cell culture. For DNA extractions, T. thermophila wild-type strain BVII and nullisomic strains CU371 (nulli 1L, 2R), CU373 (nulli 1R), CU359 (nulli 2, 3, 5), CU361 (nulli 3), CU358 (nulli 3, 4, 5), CU357 (nulli 4), and CU359 (nulli 5) were grown in $2 \%$ protease peptone-0.1\% yeast extract-0.003\% sequestrine (PPYS), prepared as described by Gorovsky et al. (14). Cultures in $500 \mathrm{ml}$ of medium were maintained at $29^{\circ} \mathrm{C}$ in 11 diphtheria toxin bottles and were aerated with a gas dispersion tube. For mating, strains CU399:Chx/ Chx (cy-s, VI) and CU401:Mpr/Mpr (6mp-s, VII) were grown in $500-\mathrm{ml}$ Erlenmeyer flasks containing $100 \mathrm{ml}$ of PPYS in a shaking incubator at $125 \mathrm{rpm}, 29^{\circ} \mathrm{C}$.

Subcellular fractionation. Micronuclei were separated from macronuclei by the procedure of Gorovsky et al. (14). Mitochondria were isolated by the method of Schwab-Stey et al. (27).

DNA isolation. Macronuclear DNA was extracted from the first macronuclear pellet prepared by the procedure of Gorovsky et al. (14). The pelleted nuclei were lysed in $1 \%$ sodium dodecyl sulfate (SDS) in $0.1 \times$ SSC (standard saline citrate; $1 \times$ SSC is $0.15 \mathrm{M}$ $\mathrm{NaCl}$ plus $15 \mathrm{mM}$ sodium citrate, $\mathrm{pH} 7.0$ ). The lysate was incubated for 2 to $4 \mathrm{~h}$ at $37^{\circ} \mathrm{C}$ in $100 \mu \mathrm{g}$ of pronase per $\mathrm{ml}$ and was phenol extracted, and nucleic acids were precipitated from the aqueous layer by adding 2 volumes of cold $95 \%$ ethanol. The precipitate was redissolved in $2 \times \mathrm{SSC}$ and was digested with $100 \mu \mathrm{g}$ of pancreatic RNAse A per ml-40 U of T1 RNAse per ml at $37^{\circ} \mathrm{C}$ for $1 \mathrm{~h}$. Pronase was added to a concentration of $100 \mu \mathrm{g} / \mathrm{ml}$, and digestion was continued for an additional hour. The solution was phenol extracted, and the DNA was precipitated from ethanol. DNA was isolated from mitochondria by the same procedure used for macronuclear DNA.

DNA was isolated from micronuclei by a simplified procedure in which the pelleted micronuclei were lysed in $1 \%$ SDS in $0.1 \times$ SSC. The lysate was brought to $100 \mu \mathrm{g}$ of pronase per $\mathrm{ml}$, incubated at $37^{\circ} \mathrm{C}$ for $1 \mathrm{~h}$, and phenol extracted. The DNA was precipitated by the addition of $\mathrm{NaCl}$ to $0.1 \mathrm{M}$ and 2 volumes of cold 95\% ethanol.

Construction of the plasmid bank and isolation of plasmid DNA. DNA from a preparation of micronuclei containing less than $0.3 \%$ contaminating macronuclei (6\% macronuclear DNA) was digested with the restriction enzyme HindIII. The fragments were ligated to the plasmid vector pBR322, which had been digested with HindIII and treated with calf intestine alkaline phosphatase. Transformants resistant to $20 \mu \mathrm{g}$ of ampicillin per $\mathrm{ml}$ and susceptible to $20 \mu \mathrm{g}$ of tetracycline per $\mathrm{ml}$ were stored in microtiter plates as described by Gergen et al. (11).

Plasmid DNA was prepared by the method of Meagher et al. (20), except that the ether extraction was omitted. Precipitated DNA was redissolved in 270 $\mu$ l of $5 \mathrm{mM}$ Tris- $0.25 \mathrm{mM}$ EDTA (pH 7.9) and transferred to a microfuge tube. Thirty microliters of $0.5 \mathrm{M}$ magnesium acetate-2.5 M lithium acetate was added, and the DNA was precipitated a second time by the addition of 3 volumes of $95 \%$ ethanol. Precipitated DNA was stored at $-20^{\circ} \mathrm{C}$.

Filter hybridization. DNA was digested with the restriction endonuclease HindIII (Bethesda Research Laboratories) under the conditions recommended by the supplier. DNA fragments were separated by electrophoresis through $0.7 \%$ agarose gels in $40 \mathrm{mM}$ Tris base-20 mM sodium acetate-2 $\mathrm{mM}$ disodium EDTA$18 \mathrm{mM} \mathrm{NaCl}$ (pH 8.0) buffer for $390 \mathrm{~V} \cdot \mathrm{h}$. The DNA was transferred to nitrocellulose filters by the method of Southern (28) and was probed with DNA nick translated as described by Maniatis et al. (17).

Preliminary screening of the plasmid bank for repeated mic-specific DNA sequences was carried out by a two-step sandwich hybridization procedure. Unlabeled recombinant plasmid DNA was linearized by digestion with the restriction enzyme PstI, heat denatured, and prehybridized to genomic DNA immobilized on a nitrocellulose filter in $50 \%$ formamide-5 $\times$ SSC-25 mM sodium phosphate ( $\mathrm{pH}$ 6.8)-1 $\times$ Denhardt solution-200 $\mathrm{g}$ of sonicated, alkali-denatured salmon sperm DNA per $\mathrm{ml}$ for 8 to $18 \mathrm{~h}$ at $33^{\circ} \mathrm{C}$. Excess plasmid DNA was removed by rinsing the filter in the bag with $5 \mathrm{ml}$ of hybridization solution without plasmid DNA. The filters were subsequently hybridized with radioactive plasmid pBR322 under the same 
conditions used for the first hybridization, except that incubation was at $42^{\circ} \mathrm{C}$. The probe hybridizes to the vector portion of the recombinant plasmid DNA, which is in turn hybridized to the homologous DNA fragment on the filter. This procedure obviates the necessity of separately nick translating each cloned fragment.

After hybridization, the filters were washed four times for at least $\mathbf{3 0}$ min each at increasing stringency: first wash, $5 \times \mathrm{SSC}, 1 \times$ Denhardt solution, and $0.1 \%$ SDS at $42^{\circ} \mathrm{C}$; second wash, $6 \times$ SSC and $0.1 \%$ SDS at $55^{\circ} \mathrm{C}$; third wash, $2 \times \mathrm{SSC}$ and $0.1 \%$ SDS at $55^{\circ} \mathrm{C}$; fourth wash, $2 \times \mathrm{SSC}$ at $55^{\circ} \mathrm{C}$. Putative mic-specific DNA clones were tested for homology to nick-translated mitochondrial DNA by hybridization under the same conditions as described above, at $33^{\circ} \mathrm{C}$.

Cytology. Matings were done by the method of Bruns and Brussard (7). Strains CU399 (mating type VI) and CU401 (mating type VII) were grown to a density of $2.5 \times 10^{5}$ cells per $\mathrm{ml}$ in PPYS. The cells were pelleted by centrifugation at $100 \times g$ for $1.5 \mathrm{~min}$,

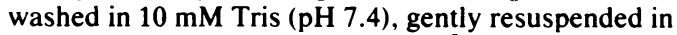
the same solution at a density of $10^{5}$ cells per $\mathrm{ml}$, and starved separately for $23 \mathrm{~h}$. The cells were counted, and equal numbers were mixed together, diluted to $8 \times$ $10^{4}$ cells per $\mathrm{ml}$, and incubated at $29^{\circ} \mathrm{C}$ without shaking to permit pairing. At $1.5 \mathrm{~h}$ after mixing, $77 \%$ of the cells were in pairs. Pairing reached $91 \%$ by $4.5 \mathrm{~h}$, at which time the cells were fixed.

Mating cells were concentrated from 100 to $0.75 \mathrm{ml}$ by centrifugation at $100 \times g$ for $1.5 \mathrm{~min}$ and were fixed for $10 \mathrm{~min}$ at room temperature by adding the concentrated cell suspension to $9 \mathrm{ml}$ of fresh Schaudinn fixative ( 2 parts of saturated $\mathrm{HgCl}_{2}, 1$ part of absolute ethanol, $1.5 \%$ glacial acetic acid). The cells were washed three times for $5 \mathrm{~min}$ in $70 \%$ ethanol. Fixed cells can be stored in $70 \%$ ethanol at $4^{\circ} \mathrm{C}$ for several days. Longer storage decreases cell spreading and chromosome dispersion when the slides are prepared.

Cells were postfixed by transferring 10 drops of the cell suspension in a pipette into $4 \mathrm{ml}$ of fresh absolute ethanol-glacial acetic acid (3:1). After $5 \mathrm{~min}$ to $1 \mathrm{~h}$, a drop of the cell suspension was allowed to fall from a height of $30 \mathrm{~cm}$ onto a clean microscope slide and was air dried.

Slides were treated before hybridization essentially by the method of Yokayama and Yao (37). They were washed for $10 \mathrm{~min}$ each in $70 \%$ ethanol, and in two washes of $0.01 \% \mathrm{I}_{2}$ in $70 \%$ ethanol (to remove excess $\mathrm{HgCl}_{2}$ ), dehydrated in 70,95 , and $100 \%$ ethanol, and air dried. The slides were then incubated for $30 \mathrm{~min}$ at $70^{\circ} \mathrm{C}$ in $2 \times \mathrm{SSC}(3)$ and rinsed three times for $10 \mathrm{~min}$ in $0.1 \mathrm{M}$ triethanolamine ( $\mathrm{pH} \mathrm{8.0)}$. Acetic anhydride was added to the third thiethanolamine rinse, with stirring (15), and the slides were dehydrated in ethanol as above. Immediately before hybridization. the slides were immersed in $0.07 \mathrm{~N} \mathrm{NaOH}-0.3 \mathrm{M} \mathrm{NaCl}$ for 2.5 min to denature the DNA and then were dehydrated by passage through ethanol.

Hybridizations were done in dextran sulfate by the method of Yokoyama and Yao (37) except that salmon sperm DNA at a final concentration of $200 \mu \mathrm{g} / \mathrm{ml}$ was the carrier DNA. Plasmid DNA to be used as a probe and pBR322 DNA to be used as a control were nick translated with $\left[{ }^{3} \mathrm{H}\right] \mathrm{dTTP}(97 \mathrm{Ci} / \mathrm{mmol})$ to specific activities of $6.5 \times 10^{6}$ and $5 \times 10^{6} \mathrm{dpm} / \mu \mathrm{g}$, respectively. Hybridization solution $(68 \mu \mathrm{l})$ was placed on a slide and covered with a cover slip ( 22 by $50 \mathrm{~mm}$ ), and the preparations were incubated in a moist chamber at $37^{\circ} \mathrm{C}$ for $16 \mathrm{~h}$. Cover slips were removed by dipping the slides in $2 \times$ SSC. Slides were rinsed twice for $20 \mathrm{~min}$ in $2 \times \mathrm{SSC}$ at $25^{\circ} \mathrm{C}$, three times for $20 \mathrm{~min}$ in $3 \times \mathrm{SSC}$ at $55^{\circ} \mathrm{C}$, and once for $10 \mathrm{~min}$ in $2 \times \mathrm{SSC}$ at $25^{\circ} \mathrm{C}$ and were dehydrated in ethanol. They were coated with NTB-2 emulsion, exposed for 10 to 30 days at $4^{\circ} \mathrm{C}$, developed, and stained with Giemsa stain by the method of Pardue and Gall (24).

\section{RESULTS}

Fragments with homology to a cloned DNA fragment can be detected in restricted genomic DNA by sandwich hybridization. To obtain a source of DNA fragments which was representative of the sequences in the micronuclear genome, micronuclear DNA was digested with the restriction enzyme HindIII and cloned into the HindIII site of the plasmid vector pBR322. Recombinant plasmids were taken at random and screened for the presence of mic-specific DNA sequences.

Preliminary screening of the plasmid bank was done by a new method, which is described diagrammatically in Fig. 1. Tetrahymena nuclear DNA was digested with HindIII. The fragments were separated on a $0.7 \%$ agarose gel and transferred to a nitrocellulose filter by the method of Southern (28; Fig. 1a). The plasmid we used was pTtIC6, which contained a 3.5-kb fragment of Tetrahymena DNA inserted at the HindIII site of pBR322. Digestion of the plasmid DNA showed that the insert did not contain any sites recognized by the restriction enzyme PstI. The plasmid DNA was linearized by digestion with PstI, which recognizes a single site in pBR322. The restricted plasmid DNA was denatured and hybridized to the homologous Tetrahymena DNA on the filter (Fig. 1b). Nick-translated pBR322 was subsequently hybridized to the vector portion of the plasmid (Fig. 1c) and detected by autoradiography.

Figure 2 shows that the presence of unlabeled plasmid DNA, with vector covalently linked to the cloned fragment, was required to obtain a signal by sandwich hybridization. Each of the three filters shown in Fig. 2 had bound to it DNA transferred from two lanes of an agarose gel, each containing $2 \mu \mathrm{g}$ of Tetrahymena macronuclear DNA digested with HindIII. In every case, plasmid pBR322 restricted with HindIII was included in the DNA sample on the left as a positive control for hybridization. The filters differed in the presence or treatment of the plasmid DNA in the middle of the sandwich. They were all probed with radioactive pBR322 DNA.

The left lane of every pair had a band at $4.3 \mathrm{~kb}$ which resulted from hybridization of the nicktranslated plasmid pBR322 to pBR322 DNA on 

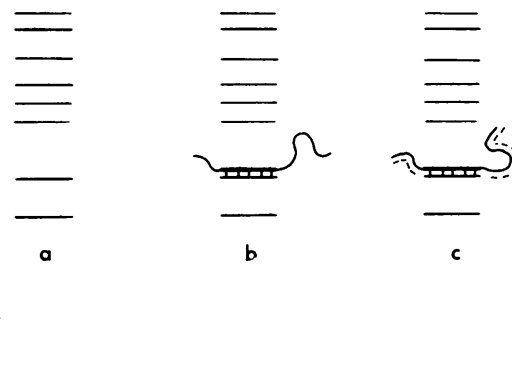

FIG. 1. Diagram of sandwich hybridization. The circle represents a fragment of Tetrahymena genomic DNA (heavy line) inserted at the HindIII site of plasmid pBR322 (light line). P indicates the presence of a PstI site 779 base pairs from the HindIII site. (a) Restriction fragments of Tetrahymena genomic DNA immobilized on a filter; (b) insert portion of the plasmid hybridized to the homologous DNA on the filter; (c) nick-translated vector DNA hybridized to the vector portion of the plasmid.

the filter. Filter a in Fig. 2 was prehybridized in the absence of unlabeled plasmid DNA. The right lane of this filter shows that pBR322 has no detectable homology with Tetrahymena DNA under these conditions of hybridization.

The filters in Fig. $2 b$ and $c$ were prehybridized in the presence of unlabeled plasmid DNA consisting of the 3.5-kb fragment of Tetrahymena DNA cloned in pBR322. Plasmid DNA used to prehybridize filter $\mathrm{b}$ was linearized by digestion with the restriction enzyme PstI. Prehybridization with unlabeled plasmid DNA permits sandwich hybridization of the pBR322 DNA to the Tetrahymena DNA on the filter and produces a band at $3.5 \mathrm{~kb}$.

The critical control for this experiment is shown for filter $\mathrm{c}$. This filter was prehybridized with the sample of plasmid DNA which had been digested with both PstI and HindIII. Digestion with HindIII separates the vector portion of the plasmid from the insert. Thus, although the Tetrahymena DNA insert is presumably hybridized to the homologous DNA on the filter, the vector tails have been removed, preventing sandwich hybridization. The lack of a band at $3.5 \mathrm{~kb}$ in filter c strongly indicates that this band was a result of sandwich hybridization in filter $b$.

Preliminary characterization of a partial plasmid bank of Tetrahymena micronuclear DNA. The method of cloning we chose was expected to yield an assortment of plasmids which were a random sample of the sequences in the micronuclear (germ line) genome. To date we have analyzed 68 clones by the sandwich hybridization procedure. Since we have not yet been able to achieve reproducible single-copy sensitivity with this method, it was most useful for the detection of sequences which were repeated in the genome.
One of the 68 plasmids contained a sequence which was repeated in both micronuclear and macronuclear DNA. We have tentatively identified 16 clones ( $23 \%$ of the sample) as micspecific. Each of the 16 was homologous to a different family of mic-specific DNA sequences which were repeated in the micronuclear genome as shown by the intensity of hybridization and by homology of the cloned DNA fragment to several fragments in restricted micronuclear DNA. An example of a cloned fragment which was shown by sandwich hybridization to belong to a family of mic-specific sequences is presented in Fig. 3. Two single-copy mic-specific sequences have been isolated by subcloning plasmids which contained repeated mic-specific elements.

Of the 51 cloned fragments which gave no signal in sandwich hybridization, 8 were rescreened by standard methods. Seven fragments hybridized to single bands of the same size in micro- and macronuclear DNA. One sequence hybridized to six HindIII fragments in micronuclear DNA which were rearranged to three different HindIII fragments in the macronuclear DNA. Rescreening did not reveal any additional single-copy mic-specific sequences.

The mic-specific sequences we have isolated are not homologous to mitochondrial DNA. To obtain

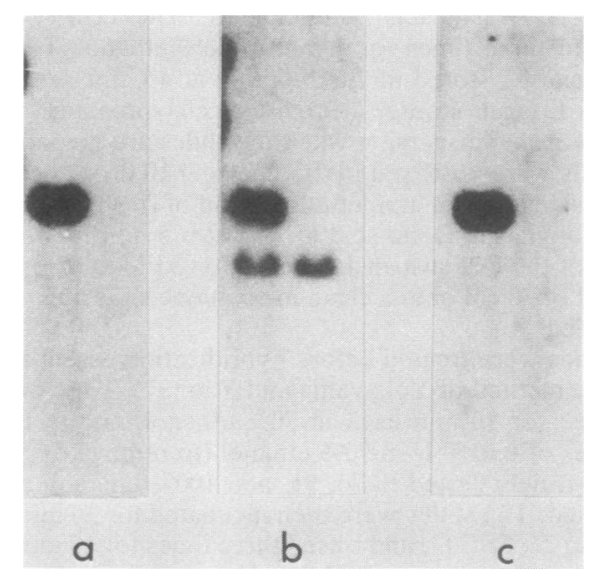

FIG. 2. Sandwich hybridization. Three identical filters with $2 \mu \mathrm{g}$ of HindIII-digested Tetrahymena DNA in each lane, transferred from an agarose gel by the method of Southern (28). The left lane on each filter also contains HindIII-digested plasmid pBR322 DNA as an internal control. Filter a was prehybridized in the absence of plasmid DNA. Filters $b$ and $c$ were prehybridized with DNA from the plasmid pTtIC6, a 3.5-kb fragment of Tetrahymena DNA inserted at the HindIII site of pBR322. In both cases, the plasmid DNA was digested with PstI. The plasmid DNA used to prehybridize filter $\mathrm{c}$ was digested with HindIII in addition. Each filter was hybridized with $1.2 \times 10^{7}$ cpm of nick-translated pBR322 DNA. 
micronuclear DNA for cloning, micro- and macronuclei were separated by differential centrifugation by the procedure of Gorovsky et al. (14). Since isolated mitochondria of Tetrahymena pyriformis have been reported to be nearly as large as the micronucleus (27), we were concerned that mitochondria might have copurified with the micronuclei and that some of the micspecific DNA sequences we had identified might therefore actually be mitochondrial in origin.

To eliminate this possibility, we prepared mitochondria by the procedure of Schwab-Stey et al. (27) and isolated the DNA. The DNA was identified as mitochondrial by comparing its restriction map with the published maps for the restriction enzymes EcoRI and HindIII (23). Clones of putative mic-specific DNA were digested with HindIII. The DNA was electrophoresed on an agarose gel and transferred to a nitrocellulose filter with restricted mitochondrial

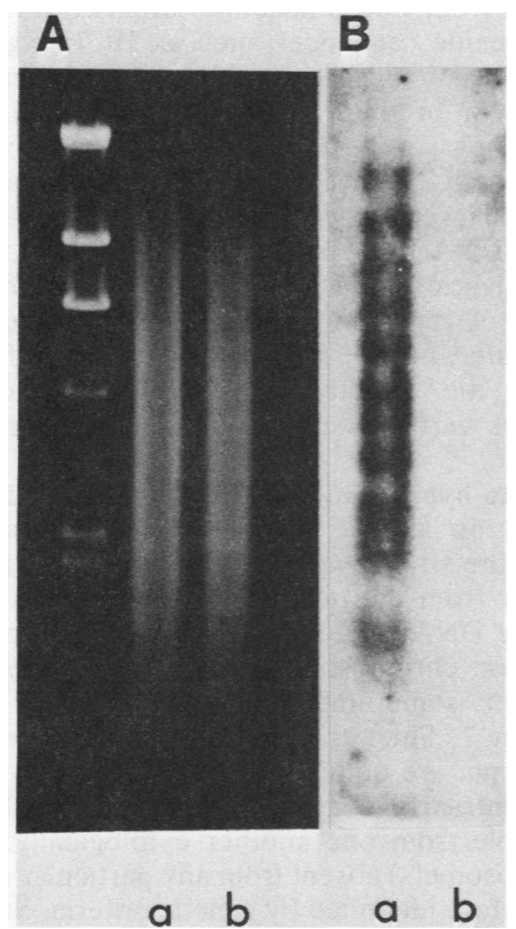

FIG. 3. HindIII digests of equal amounts of Tetrahymena micro- and macronuclear DNA. The fragments were separated by electrophoresis on an agarose gel. The DNA was transferred to a nitrocellulose filter and hybridized by the sandwich procedure to nick-translated plasmid pBR322 in the presence of the pBR322 plasmid carrying the Tetrahymena DNA insert IC1. (A) Ethidium bromide-stained gel of HindIIIdigested $\lambda$ phage DNA, micronuclear DNA (a), and macronuclear DNA (b). (B) Autoradiogram of the filter after hybridization. There is no hybridization of the mic-specific sequence IC1 to macronuclear DNA.
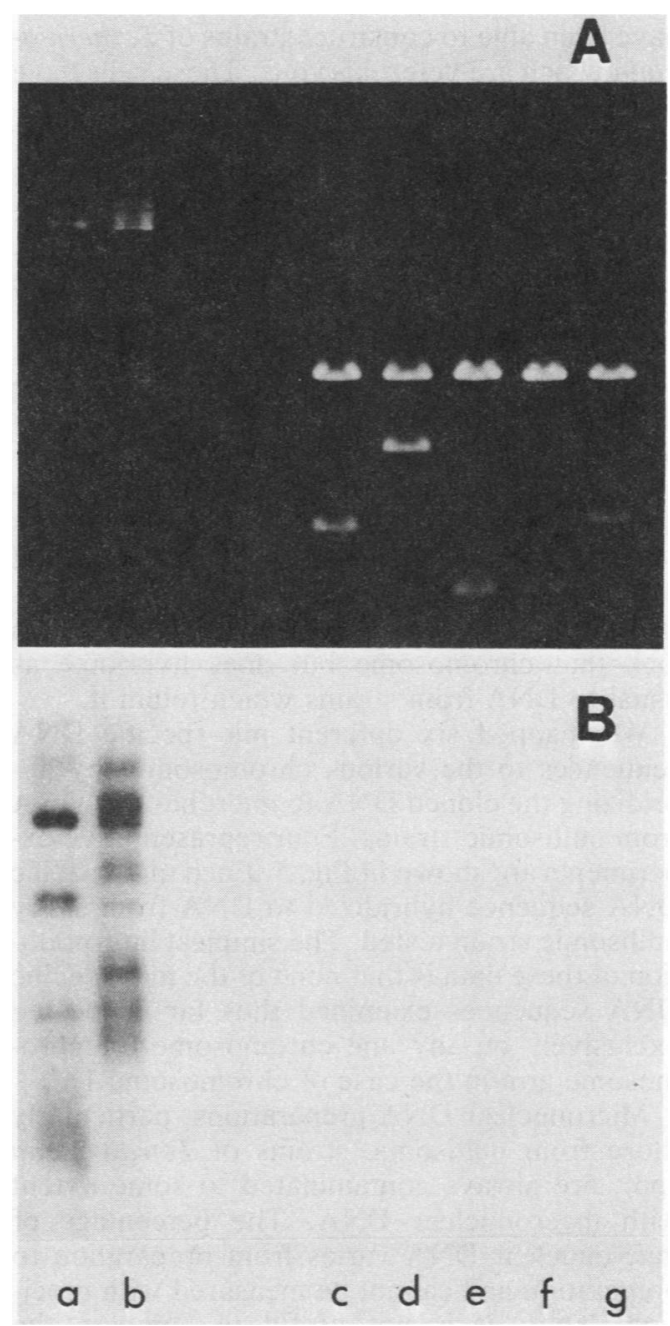

FIG. 4. Mitochondrial DNA (lane a) and several plasmids containing mic-specific Tetrahymena DNA sequences (lanes $c$ through $g$ ) digested with HindIII and run on an agarose gel. The DNA was transferred to a nitrocellulose filter and hybridized with nicktranslated mitochondrial DNA. (A) Ethidium bromidestained gel. The upper band in lanes $c$ through $g$ is pBR322, and the lower band is the Tetrahymena DNA insert (c, IIA8; d, IIIB4; e, IC1; f, ID10; g, IIC7). (B) Autoradiogram of the filter after hybridization with mitochondrial DNA. There is no homology with putative mic-specific DNA sequences, indicating they are not mitochondrial in origin. Lane b contains mitochondrial DNA partially digested with EcoRI.

DNA as a positive control. Nick-translated mitochondrial DNA did not hybridize to any of the mic-specific DNA sequences tested (Fig. 4).

Mic-specific DNA sequences are present on more than one chromosome. Certain features of the genetics of $T$. thermophila allow one to map any particular DNA sequence to one or more of the five micronuclear chromosomes by Southern blot analysis. Peter Bruns and his colleagues 
have been able to construct strains of $T$. thermophila which are heterokaryons. These cells have the normal complement of DNA in the macronucleus but are lacking one or more pairs of chromosomes in the micronucleus (8). Since the macronucleus is the site of most, if not all, of the transcriptional activity in a vegetative cell (13, 19), the cells are viable as long as they are maintained in the vegetative state.

The availability of these cell lines provides an opportunity for mapping DNA sequences to the five Tetrahymena chromosomes. In this method, a particular DNA sequence is hybridized to micronuclear DNA from various strains which are lacking different combinations of chromosomes. Any DNA sequence which is derived from a particular chromosome does not hybridize to micronuclear DNA from strains which lack that chromosome but does hybridize as usual to DNA from strains which retain it.

We mapped six different mic-specific DNA sequences to the various chromosomes by hybridizing the cloned DNA to micronuclear DNA from nullisomic strains. Four representative experiments are shown in Fig. 5. Each mic-specific DNA sequence hybridized to DNA from every nullisomic strain tested. The simplest interpretation of these data is that none of the mic-specific DNA sequences examined thus far is located exclusively on any one chromosome (or chromosome arm in the case of chromosome 1).

Micronuclear DNA preparations, particularly those from nullisomic strains of Tetrahymena spp., are always contaminated to some extent with macronuclear DNA. The percentage of macronuclear DNA varies from preparation to preparation and cannot be measured with precision. Thus, it is not useful to compare the intensities of hybridization from lane to lane. It is, however, valid to compare the relative intensities of several bands within a lane.

Changes in the relative intensity of various bands from one nullisomic strain to another are indicative of unequal distribution of the members of a family of repeated sequences on the five micronuclear chromosomes. The mic-specific sequence IIA8, for example, hybridized primarily to two HindIII fragments in genomic DNA of 2 and $4 \mathrm{~kb}$. Both of these fragments are repeated in the micronuclear genome as judged by the intensity of hybridization. In the micronuclear DNA from wild-type cells and from most nullisomic strains, the probe hybridized with slightly greater intensity to the $2-\mathrm{kb}$ band. However, hybridization to the 4-kb band was stronger in micronuclear DNA from strain CU373, which is nullisomic for $1 R$, indicating that the 2-kb fragment is present in a disproportionately large amount on the right arm of chromosome 1 (Fig. 5A, lane b).
A similar observation was made in the case of the mic-specific sequence IB6 (Fig. 5B). This clone hybridized strongly to a band at $1.3 \mathrm{~kb}$ in micronuclear DNA from wild-type and from most nullisomic strains. In the micronuclear DNA from these strains, there was also hybridization with much lower intensity to several other bands (arrows), including one at $1.6 \mathrm{~kb}$. In the micronuclear DNA from strain CU373, however, the band at $1.3 \mathrm{~kb}$ hybridized at lower intensity relative to the larger fragments, particularly the fragment at $1.6 \mathrm{~kb}$. The simplest interpretation of these data is that the copy number of the 1.3-kb IB6 fragment was reduced in the strain lacking the right arm of chromosome 1 . The same result was obtained in two independent experiments and was therefore unlikely to be due to incomplete digestion of the DNA.

For those mic-specific sequences which are members of large families of repeated sequences, the patterns of hybridization were very similar from one nullisomic strain to another. Mic-specific sequences such as IIC7 (Fig. 5C) hybridized to a large number of fragments so that most of them were not resolved on the autoradiogram. In the case of the mic-specific sequence IC1, however, (Fig. 3 and 5D), individual bands were absent from or underrepresented in the DNA from particular nullisomic strains. This suggests that the various members of the family of repeated sequences were unequally distributed on the five chromosomes and supported the hypothesis that mic-specific sequences were present on more than one chromosome.

In situ hybridization demonstrates that IIA8 is present on all five Tetrahymena chromosomes. Given the strains we have examined thus far, it is clear from the nullisomic mapping that micspecific DNA sequences are not located exclusively on chromosome $2,3,4$, or 5 . There is, however, some ambiguity with regard to chromosome 1. Since the chromosomes of Tetrahymena spp. are quite small and since all five are metacentric (Fig. 6a), they are not readily distinguishable from one another cytologically. The chromosome(s) absent from any particular strain is therefore identified by genetic criteria. Strains which are identified as lacking one chromosome arm, such as CU371 and CU373, may well retain any part of that arm for which there are no genetic markers, such as centromeric heterochromatin. Thus, one possible, albeit unlikely, interpretation of the data in Fig. 5 is that micspecific DNA sequences are located exclusively in centromeric heterochromatin on chromosome 1.

To eliminate the ambiguity in the nullisomic mapping, we mapped the repeated sequence 


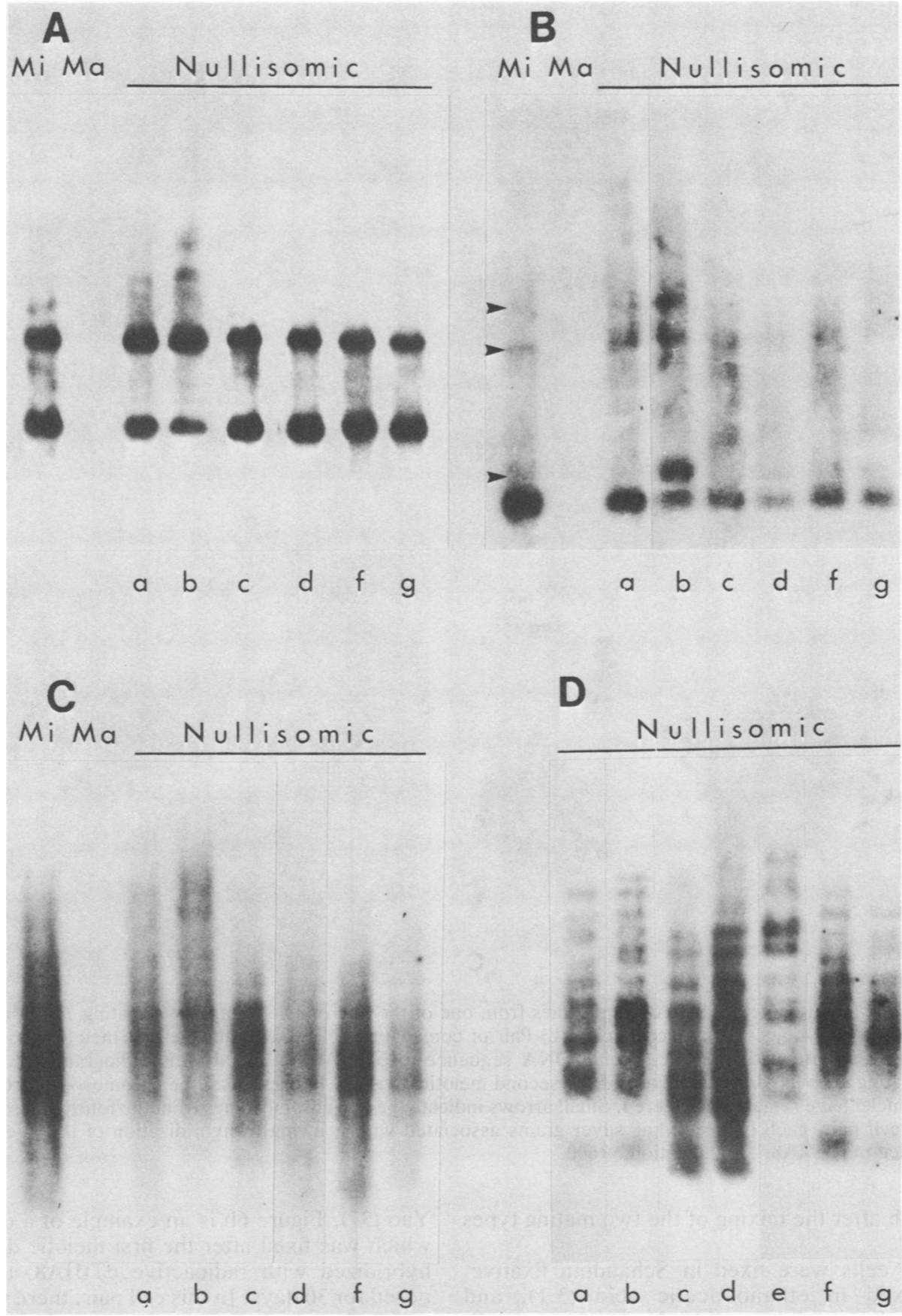

FIG. 5. Hybridization of mic-specific DNA sequences to HindIII-digested micronuclear and macronuclear DNA and to micronuclear DNA from strains nullisomic for chromosome(s) as follows: lane a, $1 \mathrm{~L}, 2 \mathrm{R}$; lane b, 1R; lane $\mathrm{c}, 2,3,5$; lane $\mathrm{d}, 3,4,5$; lane $\mathrm{e}, 3$; lane $\mathrm{f}, 4$; lane $\mathrm{g}, 5$. The nick-translated plasmids used to probe the filters were pTtIIA8 (A), pTtIB6 (B), pTtIIC7 (C), and pTtIC1 (D).

IIA 8 to all five Tetrahymena chromosomes by in situ hybridization. Optimal morphology chromosome was obtained by fixing conjugating cells during meiosis. Strains CU399 (mating type VI) and CU401 (mating type VII) were starved over-

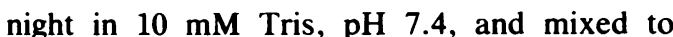
induce conjugation (7). We obtained the best chromosomes from cells at metaphase of the second meiotic division. To maximize the number of cells at this stage, mating pairs were fixed 

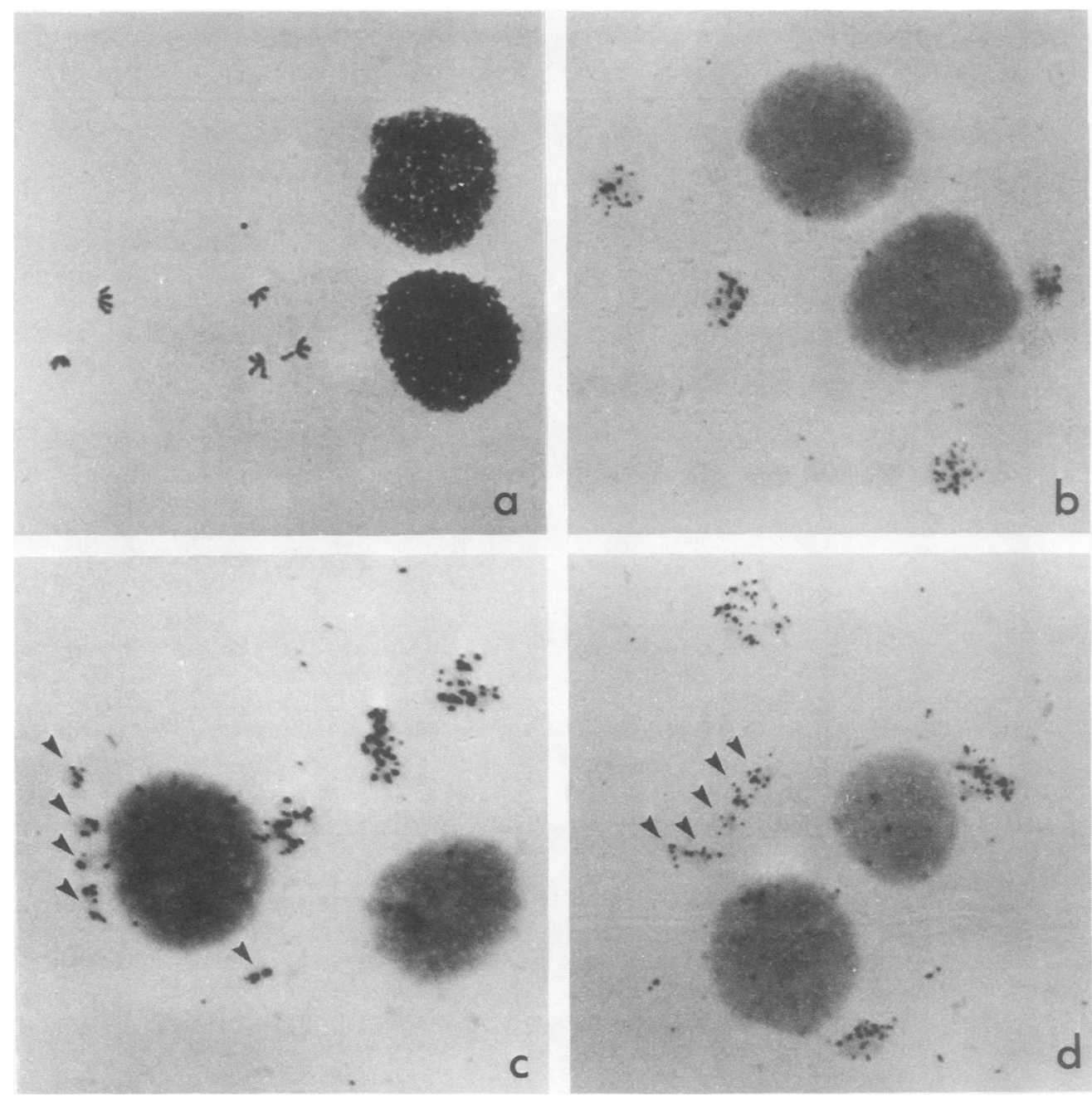

FIG. 6. (a) Five metacentric chromosomes from one of the micronuclei in a pair of mating $T$. thermophila. The large round objects are macronuclei. (b) Pair of conjugating cells fixed after the first meiotic division and hybridized in situ with the mic-specific DNA sequence in pTtIIA8. (c and d) Autoradiographs of pairs of conjugating cells fixed at metaphase of the second meiotic division. In each case, the chromosomes from three micronuclei have remained clustered. Small arrows indicate the five chromosomes from the fourth micronucleus in the cell pair, each of which has silver grains associated with it owing to hybridization of the mic-specific sequence in pTtIIA8. Magnification, $\times 600$.

at $4.5 \mathrm{~h}$ after the mixing of the two mating types (18).

The cells were fixed in Schaudinn fixative, postfixed in ethanol-acetic acid (3:1), and dropped onto a clean slide. Under these conditions, the bivalents from each of the micronuclei in a cell pair tended to remain clustered. This was important for the identification of the five chromosomes which compose one complete set among all of the chromosomes from the several micronuclei in a given cell pair.

The plasmid pTtIIA8 was nick translated with $\left[{ }^{3} \mathrm{H}\right] \mathrm{dTTP}$ and hybridized to the cytological preparations by the method of Yokoyama and
Yao (37). Figure $6 \mathrm{~b}$ is an example of a cell pair which was fixed after the first meiotic division, hybridized with radioactive pTtIIA8, and exposed for 30 days. In this cell pair, there were 15 to 34 silver grains exposed in the photographic emulsion over each of the four micronuclei, whereas the macronuclei had background levels of 2 and 4 silver grains. This result is representative of the cell pairs observed on several different slides. The mean number of silver grains counted over micronuclei was $27 \pm 8$, and over macronuclei in the same cell pairs only $5 \pm$ 3 (Table 1), even though the macronuclei contain 20 times as much DNA at this stage. Preferential 
labeling of micronuclei by in situ hybridization was consistent with the molecular data, which indicated that IIA8 is a mic-specific sequence.

Figures $6 c$ and $d$ are examples of cell pairs fixed at metaphase II and hybridized with radiolabeled pTtIIA8. In each cell pair, the chromosomes from three of the micronuclei remained closely associated, and chromosomes within a micronucleus were not distinguishable under the silver grains in the overlying emulsion. The five bivalents from the fourth micronucleus (Fig. 6c and d, arrows) were more widely separated, and 4 to 10 silver grains were associated with each of them (Table 1 , cells pairs 6 ), indicating that the mic-specific sequence pTtIIA8 is present on each of the five micronuclear chromosomes in $T$. thermophila. Since the chromosomes are very small, the resolution of this technique does not allow us to draw any conclusions regarding the localization of this sequence along the length of the chromosomes.

As a control, slides were prepared and hybridized in parallel with radiolabeled pBR322. These preparations did not show significant numbers of silver grains over the micronuclei or the micronuclear chromosomes. This strongly suggested that the hybridization observed with the plasmid pTtIIA8 can be ascribed to the inserted fragment of Tetrahymena DNA and cannot be accounted for by nonspecific association of the vector DNA sequences with anything in the cytological preparation.

\section{DISCUSSION}

We have been studying the structure and chromosomal location of germ line-specific DNA in the micronucleus of the ciliated protozoan Tetrahymena spp. To this end, we have constructed a partial plasmid bank of $T$. thermophila micronuclear DNA digested with HindIII and cloned into the HindIII site of plasmid pBR322. This method is expected to produce clones which are a random representation of the sequences in the Tetrahymena genome. Preliminary screening of the plasmid bank was done by sandwich hybridization. Of the 68 clones tested by this method, $16(23 \%)$ showed mic-specific hybridization. One cloned fragment hybridized to DNA which was repeated in both the microand macronucleus. These results are consistent with the data of Yao and Gorovsky (34), who concluded from renaturation kinetics that moderately repeated sequences in the micronucleus were absent or underreplicated in the macronucleus.

The major goal of this work was to map the chromosomal location of mic-specific DNA sequences in Tetrahymena spp. Cytological analysis indicates that the germ line-limited DNA sequences in most organisms are organized as
TABLE 1. In situ hybridization of mic-specific sequence pTtIIA8 to conjugating $T$. thermophila

\begin{tabular}{|c|c|c|c|c|c|c|c|}
\hline \multirow{3}{*}{ Slide } & \multirow{3}{*}{ Cell pair } & \multicolumn{6}{|c|}{ No. of silver grains } \\
\hline & & \multicolumn{4}{|c|}{ Micronuclei } & \multicolumn{2}{|c|}{$\begin{array}{l}\text { Macro- } \\
\text { nuclei }\end{array}$} \\
\hline & & 1 & 2 & 3 & 4 & 1 & 2 \\
\hline 1 & $\begin{array}{l}1 \\
2 \\
3 \\
4 \\
5 \\
6\end{array}$ & $\begin{array}{l}15 \\
29 \\
30 \\
22 \\
23 \\
33\end{array}$ & $\begin{array}{l}34 \\
28 \\
37 \\
21 \\
20 \\
38\end{array}$ & $\begin{array}{l}27 \\
40 \\
23 \\
25 \\
36 \\
26\end{array}$ & $\begin{array}{c}26 \\
33 \\
31 \\
25 \\
10 \\
6+10+4+6+5\end{array}$ & $\begin{array}{l}4 \\
3 \\
2 \\
5 \\
4 \\
1\end{array}$ & $\begin{array}{r}2 \\
4 \\
3 \\
3 \\
3 \\
12\end{array}$ \\
\hline 2 & $\begin{array}{l}1 \\
2 \\
3 \\
4 \\
5 \\
6\end{array}$ & $\begin{array}{l}23 \\
12 \\
29 \\
40 \\
25 \\
37\end{array}$ & $\begin{array}{l}30 \\
20 \\
24 \\
33 \\
21 \\
27\end{array}$ & $\begin{array}{l}43 \\
16 \\
17 \\
31 \\
31 \\
34 \\
34\end{array}$ & $\begin{array}{c}21 \\
13 \\
27 \\
27 \\
29 \\
5+6+5+8+8\end{array}$ & $\begin{array}{l}4 \\
4 \\
7 \\
8 \\
8 \\
3 \\
3\end{array}$ & $\begin{array}{l}9 \\
6 \\
8 \\
3 \\
4 \\
7\end{array}$ \\
\hline
\end{tabular}

large blocks of contiguous sequences. At one extreme are several members of the insect family Cecidomyiidae, which eliminate entire chromosomes from the soma $(1,22)$. In the nematode Ascaris spp. (5), in which most of the germ linespecific DNA belongs to families of short, tandemly repeated sequences (26), and in the crustacean Cyclops spp. (2), the bulk of the eliminated DNA sequences are present in the germ line as blocks of heterochromatin at the termini or near the centromeres of the chromosomes. We wanted to determine whether the germ line-specific DNA in Tetrahymena spp. is distributed over the chromosomes, as in the nematodes and crustaceans, or concentrated on a germ line-specific chromosome, as in the insects.

Hybridization of mic-specific DNA sequences to micronuclear DNA from nullisomic strains of Tetrahymena spp. suggests that each of the six sequences we have tested by this method is present on more than one chromosome. One mic-specific DNA sequence has been shown by in situ hybridization to be present on all five chromosomes. These data place certain constraints on the possible models for the arrangement of germ line-specific sequences in the micronucleus and for the mechanisms by which they are eliminated from the macronucleus.

The evidence clearly excludes a model whereby Tetrahymena spp. eliminates one of the five germ line chromosomes and supports a model of chromosome fragmentation similar to the one originally proposed by Yao and Gall (33). Thus, the characteristics which distinguish mic-specific DNA from sequences which are retained in the developing macronuclear anlagen must operate subchromosomally, perhaps at the level of DNA sequence or modification. Yao (30) 
reached this conclusion by the analysis of linkage relationships between members of a family of mic-specific DNA sequences associated with $\mathrm{C}_{4} \mathrm{~A}_{2}$ repeats.

Yokoyama and Yao (37) have presented evidence that mic-specific DNA is replicated a few times early in the formation of the macronuclear anlagen and is then eliminated, presumably by specific degradation, before any nuclear division occurs. Two laboratories $(21,25)$ have estimated the size of the macronuclear DNA to be about $600 \mathrm{~kb}$. The simplest model which is consistent with these data and with the presence of micspecific DNA sequences on all five chromosomes is one in which in the micronucleus, relatively long stretches of mic-specific DNA alternate with DNA sequences which are retained in the macronucleus. Mic-specific DNA would be excised and degraded, and the remaining DNA would be replicated in the macronucleus, perhaps, although not necessarily, without extensive rearrangement.

We can calculate the average length of a contiguous stretch of mic-specific DNA which we would expect to find in the micronuclear genome according to the above model. The DNA content of the haploid micronucleus as determined microspectrophotometrically by Woodard et al. (J. Woodard, M. Gorovsky, and E. Kaneshiro, J. Cell Biol. 39:182a, 1968) is 0.23 pg or about $2.1 \times 10^{5} \mathrm{~kb}$. Assuming that about $20 \%$ of the micronuclear genome is absent from the macronucleus, as suggested by our data, then the complexity of macronuclear DNA (which does not contain many repeated DNA sequences) is about $1.7 \times 10^{5} \mathrm{~kb}$. If the macronuclear DNA is present in $600-\mathrm{kb}$ subchromosomal fragments, this would suggest that each of the five Tetrahymena chromosomes is fragmented into about 55 pieces in the macronucleus (25). If we postulate that the fragmentation of macronuclear DNA is largely the result of elimination of alternating mic-specific DNA sequences which are scattered over all the chromosomes, it would follow that the $4 \times 10^{4} \mathrm{~kb}$ of mic-specific DNA is in 250 to 300 tracts of approximately 140 $\mathrm{kb}$ each. The existence of relatively long stretches of mic-specific sequences in the micronuclear genome would be consistent with the observation of Yao (30) that six of seven randomly selected phages containing mic-specific DNA had only mic-specific DNA.

There is at least one family of repeated DNA sequences in the Tetrahymena genome, the repeated hexanucleotide $\mathrm{C}_{4} \mathrm{~A}_{2}$, which undergoes extensive rearrangement between the microand macronuclear DNA (31). In the original model of Yao and Gall (33), it was proposed that fragmentation of the micronuclear chromosomes occurred at or near $\mathrm{C}_{4} \mathrm{~A}_{2}$ repeats. Since subse- quent experiments show that most of the micronuclear $\mathrm{C}_{4} \mathrm{~A}_{2}$ repeats seem to be flanked on both sides by mic-specific DNA $(6,30)$, it is likely that the macronuclear $\mathrm{C}_{4} \mathrm{~A}_{2}$ repeats, which are largely present at the termini of macronuclear DNA $(6,36)$, may be added to the ends of the macronuclear DNA as the analogous $\mathrm{C}_{4} \mathrm{~A}_{4}$ repeats are in the hypotrichous ciliate Oxytricha spp. (4). This could occur either enzymatically or by rearrangement of micronuclear $\mathrm{C}_{4} \mathrm{~A}_{2}$ repeats. Whether the micronuclear $\mathrm{C}_{4} \mathrm{~A}_{2}$ repeats are eliminated or rearranged to the termini of macronuclear DNA does not affect the model offered here regarding the interspersion of mic-specific and macronucleus-retained DNA sequences in the micronuclear genome.

\section{ACKNOWLEDGMENTS}

I thank H. Nields for technical assistance, S. Stein-Gavens for mitochondrial DNA, and B. Yeaton for typing the manuscript. All of the strains used in this study were a generous gift of P. Bruns.

This work was supported by Public Health Service grant GM 27864 from the National Institutes of Health and by grant PCM-8215609 from the National Science Foundation.

\section{LITERATURE CITED}

1. Bantock, C. 1961. Chromosome elimination in Cecidomyiidae. Nature (London) 190:466-467.

2. Beerman, S. 1977 . The diminution of heterochromatic chromosomal segments in Cyclops (Crustacea, Copepoda). Chromosoma 60:297-344.

3. Bonner, J. J., and M. L. Pardue. 1976. Ecdysone-stimulated RNA synthesis in imaginal discs of Drosophila melanogaster. Chromosoma 58:87-99.

4. Boswell, R. E., L. A. Klobutcher, and D. M. Prescott. 1982. Inverted terminal repeats are added to genes during macronuclear development in Oxytricha nova. Proc. Nat. Acad. Sci. U.S.A. 79:3255-3259.

5. Boveri, T. 1892. Die Entstehung des Gegensatzes zwischen den Geschlechtszellen und den somatischen Zellen bei Ascaris megalocephala. Sitz. Ges. Morphol. Physiol. Munchen Bd. 8.

6. Brunk, C. F., S. G. S. Tsao, C. H. Diamond, P. S. Ohashi, N. N. G. Tsao, and R. E. Pearlman. 1982. Reorganization of unique and repetitive sequences during nuclear development in Tetrahymena thermophila. Can. J. Biochem. 60:847-853.

7. Bruns, P. J., and T. B. Brussard. 1974. Pair formation in Tetrahymena pyiformis, an inducible developmental system. J. Exp. Zool. 188:337-344.

8. Bruns, P. J., and T. E. B. Brussard. 1981. Nullisomic Tetrahymena: eliminating germinal chromosomes. Science 213:549-551.

9. Engberg, J., P. Andersson, V. Lieck, and J. Collins. 1976. The free rDNA molecules from Tetrahymena pyriformis GL are giant palindromes. J. Mol. Biol. 194:455-470.

10. Gall, J. G. 1974. Free ribosomal RNA genes in the macronucleus of Tetrahymena. Proc. Natl. Acad. Sci. U.S.A. 71:3078-3081.

11. Gergen, J. P., R. H. Stern, and P. C. Wensink. 1979. Filter replicas and permanent collections of recombinant DNA plasmids. Nucleic Acids Res. 7:2115-2136.

12. Gorovsky, M. A. 1980. Genome organization and reorganization in Tetrahymena. Annu. Rev. Gen. 14:203-239.

13. Gorovsky, M. A., and J. Woodard. 1969. Studies of nuclear structure and function in Tetrahymena pyriformis. I. RNA synthesis in macronuclei and micronuclei. J. Cell Biol. 42:673-682. 
14. Gorovsky, M. A., M.-C. Yao, J. B. Keevert, and G. L. Pleger. 1975. Isolation of micro- and macronuclei of Tetrahymena pyriformis. Methods Cell Biol. 9:311-327.

15. Hayashi, S., I. C. Gillam, A. D. Delaney, and G. M. Tener. 1978. Acetylation of chromosome squashes of Drosophila melanogaster decreases the background in autoradiographs from hybridization with [ ${ }^{125}$ I]-labeled RNA. J. Histochem. Cytochem. 8:677-679.

16. Karrer, K. M., and J. G. Gall. 1976. The macronuclear ribosomal DNA of Tetrahymena pyriformis is a palindrome. J. Mol. Biol. 104:421-453.

17. Maniatis, T., A. Jefirey, and D. G. Kleid. 1975. Nucleotide sequence of the rightward operator of phage $\lambda$. Proc. Nat. Acad. Sci. U.S.A. 72:1184-1188.

18. Martindale, D. W., C. D. Allis, and P. J. Bruns. 1982. Conjugation in Tetrahymena thermophila a temporal analysis of cytological stages. Exp. Cell Res. 140:227-236.

19. Mayo, K. A., and E. Orias. 1981. Further evidence for lack of gene expression in the Tetrahymena micronucleus. Genetics 98:747-762.

20. Meagher, R. B., R. C. Tait, M. Betlach, and H. W. Boyer. 1977. Protein expression in $E$. coli minicells by recombinant plasmids. Cell 10:521-536.

21. Merkulova, N. A., and S. N. Borchsenius. 1976. Replication and integration of fragments of new chains into the DNA of the infusorian Tetrahymena pyriformis GL. Mol. Biol. (Moscow) 10:875-880.

22. Nicklas, R. B. 1959. An experimental and descriptive study of chromosome elimination in Miastor Spec (Cecidomyidae: Diptera). Chromosoma 10:301-336.

23. Norton, J. D., and I. G. Jones. 1978. Restriction endonuclease mapping of mitochondrial DNA from Tetrahymena pyriformis. Biochem. Soc. Trans. 6:1054-1055.

24. Pardue, M. L., and J. G. Gall. 1975. Nucleic acid hybridization to the DNA of cytological preparations. Methods Cell Biol. 10:1-16.

25. Preer, J. R., Jr., and L. B. Preer. 1979. The size of macronuclear DNA and its relationship to models for maintaining genic balance. J. Protozool. 26:14-18.

26. Roth, G. E., and K. B. Moritz. 1981. Restriction enzyme analysis of the germ line limited DNA of Ascaris suum. Chromosoma 83:169-190.

27. Schwab-Stey, H., D. Schwab, and W. Krebs. 1971. Electron microscopic examination of isolated mitochondria of Tetrahymena pyriformis. J. Ultrastruct. Res. 37:82-93.

28. Southern, E. M. 1975 . Detection of specific sequences among DNA fragments separated by gel electrophoresis. J. Mol. Biol. 98:503-517.

29. Yao, M.-C. 1981. Ribosomal RNA gene amplification in Tetrahymena may be associated with chromosome breakage and DNA elimination. Cell 24:765-774.

30. Yao, M.-C. 1982. Elimination of specific DNA sequences from the somatic nucleus of the ciliate Tetrahymena. J. Cell Biol. 92:783-789.

31. Yao, M.-C., E. Blackburn, and J. G. Gall. 1981. Tandemly repeated C-C-C-C-A-A hexanucleotide of Tetrahymena rDNA is present elsewhere in the genome and may be related to the alteration of the somatic genome. J. Cell Biol. 90:515-520.

32. Yao, M.-C., and J. G. Gall. 1977. A single integrated gene for ribosomal RNA in a eukaryote. Tetrahymena pyriformis. Cell 12:121-132.

33. Yao, M.-C., and J. G. Gall. 1979. Alteration of the Tetrahymena genome during nuclear differentiation. J. Protozool. 26:10-13.

34. Yao, M.-C., and M. Gorovsky. 1974. Comparison of the sequences of macro- and micronuclear DNA of Tetrahymena pyriformis. Chromosoma 48:1-18.

35. Yao, M.-C., A. R. Kimmel, and M. A. Gorovsky. 1974. A small number of cistrons for ribosomal RNA in the germinal nucleus of a eukaryote. Tetrahymena pyriformis. Proc. Natl. Acad. Sci. U.S.A. 71:3082-3086.

36. Yao, M.-C., and C. H. Yao. 1981. Repeated hexanucleotide C-C-C-C-A-A is present near free ends of macronuclear DNA of Tetrahymena. Proc. Natl. Acad. Sci. U.S.A. 78:7436-7439.

37. Yokoyama, R. W., and M.-C. Yao. 1982. Elimination of DNA sequences during macronuclear differentiation in Tetrahymena thermophila, as detected by in situ hybridization. Chromosoma 85:11-22. 